\title{
An Endophytic Nodulisporium sp. from Central America Producing Volatile Organic Compounds with Both Biological and Fuel Potential
}

\author{
Riyaz-Ul-Hassan, Syed ${ }^{1}$, Gary Strobel ${ }^{2 *}$, Brad Geary ${ }^{3}$, and Joe Sears ${ }^{4}$ \\ ${ }^{1}$ Microbial Biotechnology Division, Indian Institute of Integrative Medicine (CSIR), Canal Road, Jammu-180 001, India \\ ${ }^{2}$ Department of Plant Sciences, Montana State University, Bozeman, Montana, 59717, USA \\ ${ }^{3}$ Department of Plant and Wildlife Sciences, Brigham Young University, Provo, Utah, 84602, USA \\ ${ }^{4}$ Center for Lab Services/RJ Lee Group, 2710 North $20^{\text {th }}$ Ave., Pasco, Washington, 99301, USA
}

Received: August 26, 2012 / Revised: September 7, 2012 / Accepted: September 8, 2012

A Nodulisporium sp. (Hypoxylon sp.) has been isolated as an endophyte of Thelypteris angustifolia (Broadleaf Leaf Maiden Fern) in a rainforest region of Central America. It has been identified both on the basis of its morphological characteristics and by scanning electron microscopy as well as ITS sequence analysis. The endophyte produces volatile organic compounds (VOCs) that have both fuel (mycodiesel) and use for biological control of plant disease. When grown on potato dextrose agar, the organism uniquely produces a series of ketones, including acetone; 2-pentanone; 3-hexanone, 4-methyl; 3-hexanone, 2,4dimethyl; 2-hexanone, 4-methyl, and 5-hepten, 2-one and these account for about $25 \%$ of the total VOCs. The most abundant identified VOC was 1,8 cineole, which is commonly detected in this group of organisms. Other prominent VOCs produced by this endophyte include 1-butanol, 2methyl, and phenylethanol alcohol. Moreover, of interest was the presence of cyclohexane, propyl, which is a common ingredient of diesel fuel. Furthermore, the VOCs of this isolate of Nodulisporium sp. were selectively active against a number of plant pathogens, and upon a $24 \mathrm{~h}$ exposure caused death to Phytophthora palmivora, Rhizoctonia solani, and Sclerotinia sclerotiorum and $100 \%$ inhibition to Phytophthora cinnamomi with only slight to no inhibition of the other pathogens that were tested. From this work, it is becoming increasingly apparent that each isolate of this endophytic Nodulisporium spp., including the Daldina sp. and Hypoxylon spp. teleomorphs, seems to produce its own unique set of VOCs.

Key words: Ketones, rDNA, endophyte, VOCs, mycodiesel

* Corresponding author

Phone: +406 994 5148; Fax: +406 994 7600;

E-mail: uplgs@montana.edu
Fungi are important sources of bioactive molecules for use in medicine, agriculture, and industry, and only a small fraction of these organisms have been examined for their utility $[3,11]$. What is even more striking is that molecular approaches such as metagenomics indicate that less than $5 \%$ of the fungal species present on our planet have been characterized thus far [10]. Furthermore, strain variations among the same fungal species make them more diverse and suitable for the discovery of new chemical entities, enzymes, and useful volatile organic compounds. The search is now on for novel strains of microorganisms in varied environments including extreme ecological niches like geothermal vents, hot-water springs, ocean beds, and cold desserts $[6,9,10]$.

Since time immemorial, the human race has relied upon plants not only for food but also for industrial and medicinal requirements. As the search for natural products has more recently shifted towards microorganisms, plants have again come to our rescue as they host a plethora of microorganisms known as endophytes, which are very diverse and highly metabolically active $[11,18]$. Several theories have been proposed as to why endophytes produce large numbers of novel natural products not obtained from their non-endophytic counterparts. One of the very logical concepts is that in order to evade the defense mechanism of the host plant and counter the inhibitive arsenal of the competing microorganisms, the endophyte turns on pathways that are otherwise "switched off" in the free strains $[11,13]$. Secondly, the chemical constituents of the host plant and those produced specifically as a result of the mutualistic association may be responsible for epigenetic modifications in the endophyte, thus bringing about inheritable changes in the organism that activate some of the silent biosynthetic pathways and in turn produce natural products previously not known from the organism [8]. 
Fungi are capable of producing numerous volatile organic compounds (VOCs) belonging to different chemical classes, such as terpenoids, straight-chained and branched hydrocarbons, benzene derivatives, naphthalene derivatives, cycloalkanes, alcohols, organic acids, ketones, and aldehydes $[5,8,15,17]$. These compounds often possess specific or nonspecific antimicrobial activities indicating that these gaseous substances might be involved in nature to create microenvironments that inhibit or kill the competing microorganisms $[8,12]$. Interestingly, no two organisms, however similar they are genetically and morphologically, produce the same series of VOCs under identical parameters of growth and development $[4,8]$. This opens exciting and interesting possibilities in the field of natural product research and biotechnology, where such microbes and their synthetic counterpart molecules may find use in a multitude of areas. It is also worth mentioning that many of the VOCs produced by such organisms cannot be identified by the usual methods of GC/MS, as the identification is based on library search of known molecules [8]. Therefore, there are serious possibilities that the unknown compounds produced by these organisms may represent new chemical entities.

In this report, we describe a Nodulisporium sp. (Hypoxylon sp.) as an endophyte of Thelypteris angustifolia (willd.) Proctor, from the Rio San Juan rain forest region of Central America. This organism is capable of producing a unique combination of VOCs and these possess biological activity. A discussion of both the mycodiesel (fuel) and the biological potentials of this organism is also presented.

\section{Materials ANd Methods}

\section{Isolation of the Endophyte}

Small stems of Thelypteris angustifolia (willd.) Proctor, not showing any signs of disease, were procured from the Rio San Juan area of Central America $\left(11^{\circ} 02^{\prime} 602^{\prime \prime} \mathrm{N}, 83^{\circ} 50^{\prime} 355^{\prime \prime} \mathrm{W}\right)$ transported to the laboratory in a sterile polythene bag and stored at $4^{\circ} \mathrm{C}$ until processed. Plant materials including the leaves were cut under sterile conditions into small pieces $(2-5 \mathrm{~cm})$ and surface sterilized with $90 \%$ alcohol for $2 \mathrm{~min}$. After drying under sterile laminar air flow in a biosafety hood and passing through a flame, the outer tissues were removed and the internal tissues were cut into smaller pieces of 0.5 to $1 \mathrm{~cm}$ and placed on PD Agar plates harboring a colony of 7-daysold Musocodor albus. This is a selective procedure to isolate organisms that are resistant to the toxic VOCs of M. albus. Usually, organisms growing in the presence of $M$. albus are capable of producing bioactive VOCs themselves [14, 17]. The plates were incubated at $23^{\circ} \mathrm{C}$ for three weeks. Hyphal tips of endophytes emerging out of the plant tissues were picked and plated on PDA. One endophyte of particular interest, emerging from tissues of $T$. angustifolia, was labeled Ni25-2 A. It was noted that this organism was emitting vapors that resembled those of other Nodulisporium sp., especially those producing 1,8-cineole [17]. After incubation of the fungus on PDA laced with sterilized barley seed, the fully colonized seeds were placed in $15 \%$ glycerol and stored at $-70^{\circ} \mathrm{C}$ [17]. All media and chemicals were obtained from Difco (USA) and Sigma Chem. Co. (St Louis, Mo, USA) respectfully.

For the evaluation of its growth on different sugars, the endophyte was grown on Czapek-Dox Agar $\left(\mathrm{NaNO}_{3} 3 \mathrm{~g} / \mathrm{l}, \mathrm{K}_{2} \mathrm{HPO}_{4} 1.0 \mathrm{~g} / \mathrm{l}\right.$, $\mathrm{MgSO}_{4} \cdot 7 \mathrm{H}_{2} \mathrm{O} 0.5 \mathrm{~g} / \mathrm{l}, \mathrm{KCl} 0.5 \mathrm{~g} / \mathrm{l}, \mathrm{FeSO}_{4} \cdot 7 \mathrm{H}_{2} \mathrm{O} 0.1 \mathrm{~g} / \mathrm{l}$, and Agar $15 \mathrm{~g} / \mathrm{l}$ ) supplemented with $30 \mathrm{~g} / \mathrm{l}$ of a number of individual sugars.

\section{Bioactivity Profiling}

Initially, antifungal and antibacterial activities were assessed against Staphylococcus aureus, Bacillus subtilis, Candida albicans, Fusarium solani, and Sclerotinia sclerotiorum. For this purpose, small plugs ( $3 \mathrm{~mm}$ diameter) of each test fungi were placed a centimeter away from the edge of a 7-day-old Ni25-2A culture. The bacterial and yeast cultures were streak-inoculated, starting from the edge of the colony towards the periphery of the plate. The plates were wrapped with Parafilm and incubated at $23^{\circ} \mathrm{C}$ or $37^{\circ} \mathrm{C}$ for $24-48 \mathrm{~h}$ for fungi and bacteria, respectively. Growth of the test pathogens were reported as \% inhibition as compared with their relevant controls. The bacterial and yeast cultures were visually evaluated for the amount of colony inhibition.

For the activity of the VOCs produced by Ni25-2A, an agar strip of $2 \mathrm{~cm}$ was removed from the middle of a PDA plate. Ni25-2A was inoculated on the half-moon of the medium and cultivated for 7 days at $23^{\circ} \mathrm{C}$. Plugs $(3 \mathrm{~mm})$ of each of a panel of test fungi consisting of several plant and human pathogens were placed on the other half of the plate in order to grow them under the artificial atmosphere produced by the VOCs of the endophyte [14]. The bacterial and yeast cultures were streaked individually on the opposite half of the plates. The plates were wrapped with a double layer of Parafilm and incubated at $23^{\circ} \mathrm{C}$, and the results were noted at $48 \mathrm{~h} \mathrm{[14].}$

\section{Estimation of $\mathbf{I C}_{50}$}

Several of the VOCs produced by Ni25-2A were obtained commercially. The compounds tested were 2-pentanone; 3-hexanone, 2-4-dimethyl-; 1-butanol, 2-methyl-;1,8-cineole; propionic acid, 2-methyl-; and farnesene. They were placed in a mixture according to the proportion in which they appeared in the GC/MS profile (see relative areas in Table 2). Aliquots of the mixture ranging from 0.05 to $0.5 \mu \mathrm{l} / \mathrm{ml}$ were placed in pre-sterilized $6 \mathrm{~mm}$ micro-cups at the center of the agar surface of a PDA plate having a $50 \mathrm{ml}$ headspace. Test organisms were inoculated on the plates as $3 \mathrm{~mm}$ plugs of 7-day-old cultures and on normal PDA plates as controls. Percent inhibition of fungal growth was calculated after $48 \mathrm{~h}$ of growth and plotted against the concentration of the mixture per milliliter of the airspace for each organism. The inhibitory concentration yielding $50 \%$ inhibition of fungal growth $\left(\mathrm{IC}_{50}\right)$ for each organism was calculated through extrapolation from the plots [14].

\section{Scanning Electron Microscopy}

The endophyte (Ni25-2A) was grown on gamma-irradiated carnation leaves for 3 weeks to promote the formation of fruiting bodies [17]. The samples were slowly dehydrated in ethanol, critically dried, coated with gold, and examined with an FEI XL30 SEM Field Emission Gun at $5 \mathrm{kV}$ with high vacuum mode using an EverhartThornley detector. A gaseous secondary electron detector was used 
with a spot size of 3 , at $15 \mathrm{kV}$. The temperature was $4^{\circ} \mathrm{C}$ with a chamber pressure ranging from 5 to $6 \mathrm{~T}$, providing humidity up to $100 \%$ at the sample.

\section{ITS-Based Phylogenetic Analysis}

Phylogenetic analysis of the endophyte Ni25-2A was carried out by sequencing the ITS $5.8 \mathrm{~S}$ ribosomal gene. Ni25-2A was grown on PD agar for 7 days and DNA templates were prepared by using the Prepman Ultra Sample Preparation Reagent (Applied Biosystems Inc., USA) according to the manufacturer's guidelines. Universal primer pair ITS1 (5'-TCCGTAGGTGAACCTGCGG-3') and ITS4 (5'-TCCTCCGCTTATTGATATGC-3') was used to amplify the $18 \mathrm{~S}$ ITS-5.8S region of the fungus by the polymerase chain reaction (PCR). The PCR conditions used were as follows: initial denaturation at $94^{\circ} \mathrm{C}$ for $3 \mathrm{~min}$, followed by 30 cycles of $94^{\circ} \mathrm{C}$ for $15 \mathrm{~s}, 50^{\circ} \mathrm{C}$ for $30 \mathrm{~s}, 72^{\circ} \mathrm{C}$ for $45 \mathrm{~s}$, and a final extension of $72^{\circ} \mathrm{C}$ for $5 \mathrm{~min}$. The $50 \mu \mathrm{l}$ reaction mixture contained $1 \times$ PCR buffer, $200 \mu \mathrm{M}$ each dNTP, $1.5 \mathrm{mM} \mathrm{MgCl}_{2}, 10 \mathrm{pmol}$ of each primer, $1-5 \mathrm{ng}$ of DNA, and $2.5 \mathrm{U}$ of Taq DNA polymerase. The amplified product $(5 \mu \mathrm{l})$ was visualized on $1 \%(\mathrm{w} / \mathrm{v})$ agarose gel containing $0.5 \mu \mathrm{g} / \mathrm{ml}$ of ethidium bromide, to confirm the presence of a single amplified band. The amplified products were purified by Amicon Ultra columns (Millipore, USA) and 10-20 ng were used in a $10 \mu \mathrm{l}$ sequencing reaction using the Big Dye Terminator sequencing kit (v. 3.1). The forward primer ITS1 (3.2 pmoles) was used in the cycle sequencing reaction, and 20 cycles of $96^{\circ} \mathrm{C}$ for $10 \mathrm{~s}, 50^{\circ} \mathrm{C}$ for $5 \mathrm{~s}$, and $60^{\circ} \mathrm{C}$ for 4 min were performed in a Biometra Thermocycler. The extension products were purified by ethanol precipitation, dissolved in $15 \mu \mathrm{l}$ of HiDi Formamide, incubated at $95^{\circ} \mathrm{C}$ for $1 \mathrm{~min}$, and loaded on an $\mathrm{ABI}$ Prism 377 Genetic Analyzer (Perkin-Elmer, USA) for sequencing. All the reagents for sequencing were from Applied Biosystems Inc., USA. The amplified products were sequenced and aligned with the sequences in the GenBank by the BLASTN program [1]. Relevant sequences were downloaded and aligned using the MegAlign sotware (DNASTAR, Lasergene) to construct the distance matrix. The evolutionary position of the organism was ascertained by constructing a phylogenetic tree according to Tamura et al. [16].

\section{GC/MS Analyses of Fungal VOCs}

Qualitative analysis of the VOCs produced by Ni25-2A was carried out by the methods described by Strobel et al. [14]. The organism was grown on PD agar for 10 days in a Petri dish wrapped in a two layers of Parafilm to ensure that the VOCs produced during the entire period of growth accumulated in the headspace of the fungus. A hole was drilled on one side of the plate and a baked SPME fiber (Supelco) 50/30 divinylbenzene/carburen on polydimethylsiloxane on a stable flex fiber was inserted through it and the vapour phase was adsorbed for $45 \mathrm{~min}$. The vapors were injected into a Hewlett Packard 6890 gas chromatograph containing a $30 \mathrm{~m} \times 0.25 \mathrm{~mm}$ inner diameter ZB Wax capillary column with a film thickness of $0.50 \mu \mathrm{m}$. A thermal program of $30^{\circ} \mathrm{C}$ for $2 \mathrm{~min}$ followed by an increase to $220^{\circ} \mathrm{C}$ at $5^{\circ} \mathrm{C} / \mathrm{min}$ was applied. Ultrahigh purity helium gas was used as the carrier gas and the initial column head pressure was $50 \mathrm{kPa}$. Data acquisition and data processing were performed on the Hewlett Packard CHEMSTATION software system. Initial identification of the compounds produced by the endophyte was made via library comparison using the National Institute of Standards and Technology (NIST) database, and all chemical compounds described in this report use the NIST database chemical terminology. The authenticity of several compounds identified by GC/MS was reconfirmed by GC/MS of authentic standards. Standard compounds were run in a comparable manner as the fungal samples.

\section{Results}

Evolutionary Position of Ni25-2A, a Nodulisporium sp. The fungus (Ni25-2A) that was obtained from Thelypteris angustifolia, when grown on PDA, showed unique morphological characteristics (Fig. 1). The fungus colony is initially creamy white, grows grey from the middle towards the edges as it turns old, and finally becomes brownish, being circular with sharp margins and showing ridges extending from the center to the edge of the colony. Colonies more than one month old turn brownish, with concentric rings forming towards the margin. From the reverse side of the petri plate, the color changes from creamy to light brown to dark brown as the culture grows older, accompanied by heavy sporulation. The colony attains a regular size of $4.5 \mathrm{~cm}$ in 20 days. The culture smells strongly with a mix of earthy and fruity odors.

When grown on synthetic media containing individual sugars (sucrose, maltose, sorbitol, lactose, fructose, dextrose, starch, and cellulose), the fungus showed marked variations in cultural characteristics. The organism spreads its hyphae all over the plate in contrast to making a discrete colony with a well-defined margin as it does on PDA. The best growth was observed on maltose (153\%) and the lowest on sorbitol $(67 \%)$ with respect to a PDA control. On water agar and a cellulose-based medium, the growth of the organism was insignificant (data not shown). It is also worth mentioning that the characteristic smell of the volatiles of this organism was diminished when grown on media other than PDA.

Scanning electron microscopy showed an imperfect stage of Ni25-2A resembling a Nodulisporium-like anamorph. with $0.4-1.4 \mu \mathrm{m}$ hyphae, $1.4-1.8 \times 1.8-3.3 \mu \mathrm{m}$ oval-shaped conidia, having rough surfaces and present as one-celled clusters on branched conidiophores (Fig. 1B). However, the partial 18S-ITS-5.8S ribosomal gene sequence (GenBank Accession No. JQ968613) of this organism displayed the highest sequence similarity of $99.8 \%$ and $99.2 \%$ with Hypoxylon monticulosum strains SUT116 and H206, respectively (Fig. 2). The organism also showed close relationship with Nodulisporium sp., which is the anamorphic stage of Hypoxylon sp. In the phylogenetic analyses, Ni252A and Hypoxylon monticulosum strains SUT116 formed a sister group with three different species of Daldinia (Fig. 2). However, the perfect stage of the fungus was not observed on any of the media used for its cultivation. Thus, Ni25-2A is hereafter referred to as Nodulisporium sp. 

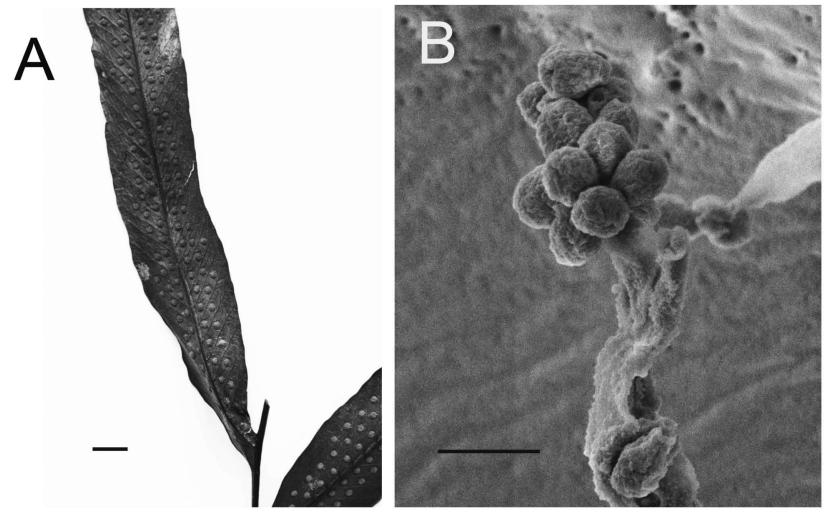

Fig. 1. Morphological characteristics of Ni25-2A.

(A) Thelypteris angustifolia or Broad Leaf Maiden Fern as the host of the endophytic fungus Nodulisporium sp. (Ni25-2A), which is the subject of this report. The bar equals $1 \mathrm{~cm}$. (B) SEM of the conidiophore of Nodulisporium sp. showing a clump of singly borne conidiophores. The bar equals $2 \mu \mathrm{m}$.

In Vitro Antimicrobial Activity of Nodulisporium sp. In co-culture, the endophyte inhibited the growth of Fusarium solani and Sclerotinia sclerotiorum by $50 \%$ and
$100 \%$, respectively. The organism also inhibited Candida albicans, whereas no activity was detected against $B$. subtilis and E. coli. Owing to its significant antimycotic activity, the activity of its VOCs was evaluated against a panel of several pathogens (Table 1). The VOCs displayed selective antimycotic activity against Phytophthora palmivora, Phytophthora cinnamomi, Rhizoctonia solani, and Sclerotinia sclerotiorum rendering them completely inhibited and nonviable except for Phytophthora cinnamomi (Table 1). The other fungal pathogens that were partially inhibited included Pythium ultimum (43\%), Aspergillus fumigatus $(20 \%)$, Botrytis cinerea (20\%), and Geotrichum candidum $(13 \%)$. The VOCs, however, showed no inhibition in case of several other bacterial and fungal strains including Candida albicans (Table 1). The latter observation suggests that the co-culture inhibition of C. albicans must be due to a nonvolatile agar diffusible substance(s).

\section{VOC Production}

The qualitative analyses of the VOCs produced by this organism were carried out after 10 days of growth on PDA. Interestingly, the most striking aspect of the analysis
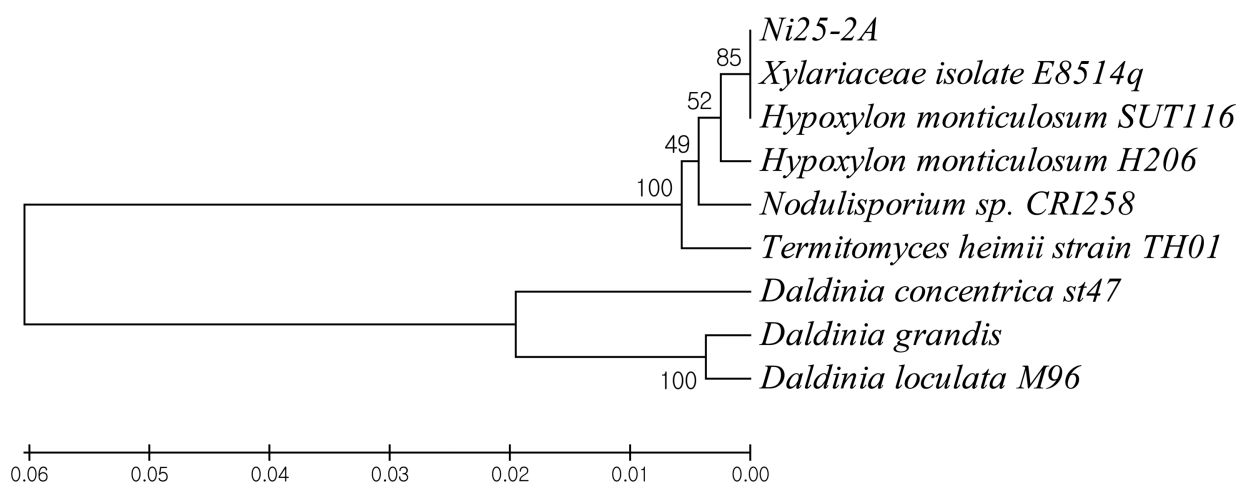

\begin{tabular}{|c|c|c|c|c|c|c|c|c|c|c|c|}
\hline \multicolumn{12}{|c|}{ Percent Identity } \\
\hline & 1 & 2 & 3 & 4 & 5 & 6 & 7 & 8 & 9 & & \multirow{11}{*}{$\begin{array}{l}\text { Daldinia concentrica } \text { st47.seq } \\
\text { Daldinia grandis.seq } \\
\text { Daldinia loculata } \text { M96.seq } \\
\text { Hypoxylon monticulosum } \text { SUT116.seq } \\
\text { Nodulisporium } \text { sp. CRI258.seq } \\
\text { Termitomyces heimii } \text { strain TH01.seq } \\
\text { Xylariaceae isolate E8514q.seq } \\
\text { Ni25-2A.seq } \\
\text { Hypoxylon monticulosum } \mathrm{H} 206\end{array}$} \\
\hline 1 & & 95.9 & 96.1 & 89.8 & 89.5 & 88.6 & 90.1 & 90.8 & 89.4 & 1 & \\
\hline 2 & 4.3 & & 99.0 & 87.2 & 87.4 & 87.0 & 87.9 & 86.9 & 86.8 & 2 & \\
\hline 3 & 4.0 & 1.0 & & 89.7 & 89.9 & 88.0 & 90.0 & 90.7 & 89.4 & 3 & \\
\hline 4 & 11.2 & 14.2 & 11.2 & & 99.2 & 98.8 & 100.0 & 99.8 & 99.4 & 4 & \\
\hline 5 & 11.4 & 13.9 & 11.0 & 0.8 & & 98.1 & 99.2 & 97.9 & 98.6 & 5 & \\
\hline 6 & 12.5 & 14.5 & 13.2 & 1.2 & 1.9 & & 98.8 & 98.8 & 98.6 & 6 & \\
\hline 7 & 10.8 & 13.3 & 10.8 & 0.0 & 0.8 & 1.2 & & 98.6 & 99.4 & 7 & \\
\hline 8 & 9.9 & 14.6 & 10.0 & 0.2 & 2.1 & 1.2 & 1.4 & & 99.2 & 8 & \\
\hline \multirow[t]{2}{*}{9} & 11.5 & 14.6 & 11.6 & 0.6 & 1.4 & 1.4 & 0.6 & 0.8 & & 9 & \\
\hline & 1 & 2 & 3 & 4 & 5 & 6 & 7 & 8 & 9 & & \\
\hline
\end{tabular}

Fig. 2. Phylogenetic analysis of Ni25-2A.

(Top) The evolutionary history of Ni25-2A (Nodulisporium sp.) was inferred using the UPGMA method [16]. The optimal tree with the sum of branch length $==0.15647555$. The percentage of replicate trees in which the associated taxa clustered together in the bootstrap test ( 500 replicates) are shown next to the branches. The tree is drawn to scale, with branch lengths in the same units as those of the evolutionary distances used to infer the phylogenetic tree. The evolutionary distances were computed using the Maximum Composite Likelihood method and are in the units of the number of base substitutions per site. All positions containing gaps and missing data were eliminated from the dataset (complete deletion option). There were a total of 408 positions in the final dataset. (Bottom) Distance matrix depicting the percent sequence identity and divergence of the $18 \mathrm{~S}-\mathrm{ITS}-5.8 \mathrm{~S}$ ribosomal gene sequence of NI25-2A with its close relatives, constructed by the MegAlign module of the DNASTAR (Lasergene) software. 
Table 1. The inhibition of test microorganisms by the VOCs of Nodulisporium sp. and the artificial mixture of the VOCs.

\begin{tabular}{|c|c|c|c|}
\hline Test organism & Percent inhibition & Viability & $\mathrm{IC}_{50}$ of Artificial VOC mix $(\mu \mathrm{l} / \mathrm{ml}$ of airspace $)$ \\
\hline Aspergillus fumigatus & $20.0 \pm 0.0 \%$ & & 0.25 \\
\hline Botrytis cinerea & $20 \pm 0.0 \%$ & & 0.15 \\
\hline Ceratocystis ulmi & $0.0 \pm 0.0 \%$ & & 0.20 \\
\hline Cercospora beticola & $0.0 \pm 0.0 \%$ & & 0.20 \\
\hline Colletrotrichum lagenarium & $0.0 \pm 0.0 \%$ & & 0.20 \\
\hline Fusarium solani & $0.0 \pm 0.0 \%$ & & 0.20 \\
\hline Geotrichum candidum & $13.3 \pm 3.5 \%$ & & 0.35 \\
\hline Phytophthora palmivora & $100 \pm 0.0 \%$ & Nonviable & 0.10 \\
\hline Phytophthora cinnamomi & $100 \pm 0.0 \%$ & Viable & 0.10 \\
\hline Pythium ultimum & $42.9 \pm 4.1 \%$ & & 0.10 \\
\hline Rhizoctonia solani & $100 \pm 0.0 \%$ & Nonviable & 0.15 \\
\hline Sclerotinia sclerotiorum & $100 \pm 0.0 \%$ & Nonviable & 0.15 \\
\hline Trichoderma viridae & $0.0 \pm 0.0 \%$ & & 0.23 \\
\hline Verticillum dahliae & $0.0 \pm 0.0 \%$ & & 0.20 \\
\hline Muscodor albus & $33.3 \pm 1.8 \%$ & & $\mathrm{ND}^{\mathrm{a}}$ \\
\hline Candida albicans & No inhibition & & ND \\
\hline Bacillus subtillus & No inhibition & & ND \\
\hline Escherichia coli & No inhibition & & ND \\
\hline
\end{tabular}

${ }^{\mathrm{a}} \mathrm{ND}=$ not determined.

The fungus was grown for 7 days on PDA on $1 / 2$ of the agar medium in a Petri plate, and then the test organism was placed on the opposite side of the plate and the $\%$ inhibition, over the control, was measured at $48 \mathrm{~h}$, as shown in this table. The viability of the test organisms was also tested. The $\mathrm{IC}_{50}$ of the artificial VOC mixture was calculated as described in the text.

was the presence of a series of ketones, for example acetone; 2-pentanone; 3-hexanone, 4-methyl-; 2-hexanone, 4-methyl-; 3-hexanone, 2-4-dimethyl-; 5-hepten-2-one, ranging from $\mathrm{C} 2$ to $\mathrm{C} 7$ compounds along with the terpenes, 1,8 -cineole and $\beta$-farnesene. In addition to these, the headspace contained several alcohols such as 1-butanol, 2methyl-; 1-hexanol, 2-ethyl-; phenylethyl alcohol; and 2naphthalinol, 3-methoxy-. Other VOCs in the mixture included 4-methyl-3-hexanol acetate and propionic acid, 2methyl-, as well as the important fuel compound cyclohexane, propyl- . The \% relative areas calculated for each compound in the $\mathrm{GC} / \mathrm{MS}$ analyses indicated that 1,8-cineole constituted the most abundant compound that was detected. The ketones collectively constituted about $25 \%$ of the total VOCs, whereas the compounds that could not be identified, thus designated here as "unknown", constituted about 39\% (Table 2).

\section{IC $_{50}$ of the Artificial VOC Mix}

Several of the compounds that were available in the market were obtained and made into an artificial mixture prepared from 2-pentanone; 3-hexanone, 2-4-dimethyl-; 1-butanol, 2-methyl-; 1,8-cineole; propionic acid, 2-methyl-; and $\beta$ -farnesene in the proportion as they appear in the GC/MS analysis of the VOCs (Table 2; see the relative abundance of the individual compounds). The artificial VOC mixture was most effective against Phytophthora palmivora, Phytophthora cinnamomi, Pythium ultimum, Rhizoctonia solani, Sclerotinia sclerotiorum, and Botrytis cinerea, with an $\mathrm{IC}_{50}$ of $0.1 \mu \mathrm{l} / \mathrm{ml}$ of the headspace for the former three pathogens and $0.15 \mu \mathrm{l} / \mathrm{ml}$ for the latter three. Interestingly, the organisms with the lowest $\mathrm{IC}_{50} \mathrm{~s}$ were also some of the most sensitive to the fungal VOCs (Table 1). All the fungal pathogens tested in this study were susceptible to the artificial VOC mix, with the highest $\mathrm{IC}_{50}$ of $0.35 \mu \mathrm{l} / \mathrm{ml}$ for Geotrichum candidum (Table 1).

\section{Discussion}

The Nodulisporium sp., in this study, was found in nature associated with Thelypteris angustifolia as an endophyte. The fungus was resistant to the VOCs produced by a standard culture of M. albus, which was taken as an indication that it too could be a VOC-producing strain [14]. This organism was placed as a Nodulisporium/Hypoxylon on the basis of its morphological characteristcs and ITS sequence analysis, although the perfect stage of this fungus was not observed under the conditions used for its cultivation.

The VOCs produced by this organism showed differential antimycotic activities, being highly active against $P$ hytophthora palmivora, Phytophthora cinnamomi, Rhizoctonia solani, and Sclerotinia sclerotiorum, and moderately or weakly active against Pythium ultimum, Aspergillus fumigatus, Botrytis cinerea, and Geotrichum candidum (Table 1). The artificial VOC mix significantly mimicked the VOC activity of the endophyte, but the unknown compounds may also have a role in inhibiting other organisms that 
Table 2. The composition of VOCs in Nodulisporium sp. as determined by GC/MS.

\begin{tabular}{|c|c|c|c|c|c|}
\hline Retention time ( $\min$ ) & Relative area & Possible compound & MW (Da) & Quality & Relative area $\%$ \\
\hline 1.95 & 0.5 & Acetone $^{\mathrm{a}}$ & 58 & 78 & 2.39 \\
\hline 3.87 & 0.2 & Unknown & 281 & & 0.96 \\
\hline 4.08 & 0.3 & 2-Pentanone ${ }^{a}$ & 86 & 72 & 1.44 \\
\hline 6.13 & 0.4 & 3-Hexanone, 4-methyl- & 114 & 80 & 1.91 \\
\hline 6.28 & 1.1 & 3-Hexanone, 2-4-dimethyl- ${ }^{a}$ & 128 & 83 & 5.26 \\
\hline 6.86 & 0.1 & Unknown & 72 & & 0.48 \\
\hline 7.22 & 1 & 2-Hexanone, 4-methyl- & 114 & 91 & 4.78 \\
\hline 7.28 & 0.7 & Ethylbenzene $^{\mathrm{b}}$ & 106 & 80 & 3.35 \\
\hline 7.65 & 0.2 & Unknown & 98 & & 0.96 \\
\hline 8.78 & 0.4 & Cyclohexane, propyl- & 126 & 72 & 1.91 \\
\hline 9.75 & 1.7 & 1-Butanol, 2-methyl- ${ }^{\mathrm{a}}$ & 88 & 78 & 8.13 \\
\hline 9.37 & 2.7 & $1,8-$ Cineole $^{a}$ & 154 & 99 & 12.92 \\
\hline 9.87 & 0.2 & 4-Methyl-3-hexanol acetate & 158 & 74 & 0.96 \\
\hline 10.74 & 2 & 5-Hepten-2-one & 112 & 90 & 9.57 \\
\hline 11.18 & 0.8 & Unknown & 172 & & 3.83 \\
\hline 11.61 & 0.3 & Unknown & 128 & & 1.44 \\
\hline 16.24 & 0.4 & Unknown & 170 & & 1.91 \\
\hline 16.4 & 0.7 & Unknown & 112 & & 3.34 \\
\hline 16.84 & 0.2 & Unknown & 180 & & 0.96 \\
\hline 17.15 & 0.2 & 1-Hexanol, 2-ethyl & 130 & 78 & 0.96 \\
\hline 19.51 & 0.2 & Propionic acid, 2-methyl- ${ }^{\mathrm{a}}$ & 88 & 86 & 0.96 \\
\hline 19.76 & 0.3 & Unknown & 153 & & 1.44 \\
\hline 20.03 & 0.3 & Unknown & 153 & & 1.44 \\
\hline 20.13 & 1.1 & Unknown & 138 & & 5.26 \\
\hline 20.77 & 1.5 & Unknown & 108 & & 7.18 \\
\hline 20.32 & 0.2 & Unknown & 113 & & 0.96 \\
\hline 21.66 & 0.3 & $\beta$-Farnesene ${ }^{a}$ & 204 & 95 & 1.44 \\
\hline 23.71 & 0.6 & Unknown & 146 & & 2.87 \\
\hline 26.91 & 0.5 & Phenylethyl alcohol $^{\mathrm{a}}$ & 122 & & 2.39 \\
\hline 29.39 & 0.3 & Unknown & 94 & & 1.44 \\
\hline 34.70 & 1 & Unknown & 124 & & 4.78 \\
\hline 40.00 & 0.5 & 2-Naphthalinol, 3-methoxy- & 174 & 91 & 2.39 \\
\hline
\end{tabular}

${ }^{a}$ These compounds had their identity confirmed by use of an authentic standard that was subjected to the same GC/MS conditions as the fungal preparation.

${ }^{\mathrm{b}}$ Trace amounts of this compound were also found in the control PDA plate gas mixture.

obviously could not be evaluated (Table 1). The selective activity of the VOCs of this organism may be exploited for inhibition of specific phytopathogens for disease management of agricultural crops. However, it is imperative to learn if this organism can act as a phytopathogen in the crop of interest. Volatile organic compounds are important infochemicals and various fungi produce interesting arrays of compounds that inhibit other microorganisms.

Among the VOCs of Nodulisporium sp. is a vast range of compounds that have fuel potential (mycodiesel) $[5,8$, $15,17]$. Comparable to the endophyte, also identified as Hypoxylon sp. (Nodulisporium sp.), this organism also produces 1,8-cineole and a cyclohexane derivative (cyclohexane, propyl-) [17]. The latter is also present in petroleum distillate and the former could be an excellent fuel additive [2]. $\beta$-Farnesene is an important fuel candidate, as its fully reduced form is being pursued as an alternate biofuel [7]. The uniqueness of this organism is the production of short- chain ketones, which are the oxidized forms of many straight-chain alkanes and branched alkanes present in crude oil. In addition, a series of alcohols produced by this endophyte are also fuel-like compounds produced by fungi (Table 2). With data accumulating on fuel-like compounds produced by microorganisms, the theory that microorganisms may have played a role in the production of crude oil seems increasingly likely $[5,8]$. It is quite possible that heat and the reductive conditions found in the earth could have been responsible for further conversion of the more oxidized fungal products (i.e., ketones, alkyl alcohols, and aldehydes) to the more reduced chemical forms, the hydrocarbons [5]. The limitation for practical applications of these fungal VOCs is the relatively low production of these substances by fungi. However, with the intervention of metabolic pathway engineering and fermentation technology, it seems that these fuel-like compounds could be produced on a large scale in the 
future. In nature, these compounds may be helping the host plant in evading infection from other microorganisms. $\beta$ Farnesene may be also playing a role as an insect repellent, preventing infestation of the host by aphids [19]. Thus, the process of natural selection may promote the association of such endophytes with the host plants.

In conclusion, the Nodulisporium sp. in this study produces a unique and wide range of bioactive VOCs that also possess fuel potential. It seems, to date, that each Hypoxylon /Daldinia (Nodulisporium sp.), although closely morphologically and genetically (ITS region) similar, has an ability to express a production of VOCs that is different than all others. In addition, the use of molecular biology tools such as epigenetic modulation could be used to further explore the hidden VOC-producing potential of this organism [8]. Such organisms may also be selected as candidates for metabolic engineering and scale-up processes for the production of cost-effective alternate fuels or to find biological utilities.

\section{Acknowledgments}

The authors acknowledge the support of the National Science Foundation (NSF) Emerging Frontiers in Research and Innovation (NSF-EFRI), Grant No. 0937613 to Dr. Brent Peyton and Gary Strobel of MSU and a DoE grant to GAS to carry out this work. The BOYSCAST program of India granted a 1 year fellowship to SRUH to study and work at MSU. The authors are grateful to Mr. Percy Nunez of Cusco, Peru, for generously identifying some plant materials and to Dr. Eric Vandenberghe of Managua, Nicaragua for also providing assistance in plant identification and guidance in Central America. Generous field assistance was also provided by Ms. Natasha Mallette and Mr. Eric Booth, both of Bozeman, Mt.

\section{REFERENCES}

1. Altschul, S. F., T. L. Madden, A. A. Schaffer, J. Zhang, Z. Zhang, W. Miller, and D. J. Lipman. 1997. Gapped BLAST and PSI-BLAST: A new generation of protein database search programs. Nucleic Acids Res. 25: 3389-3402.

2. Barton, A. and J. Tjandra. 1989. Eucalyptus oil as a cosolvent in water-ethanol-gasoline mixtures. Fuel 68: 11-17

3. Keller, N. P., G. Turner, and J. W. Bennett. 2005. Fungal secondary metabolism - from biochemistry to genomics. Nature Rev. Microbiol. 3: 937-947.

4. Kudalkar, P., G. Strobel, S. Riyaz-Ul-Hassan, B. Geary, and J. Sears. 2012. Muscodor sutura, a novel endophytic fungus with volatile antibiotic activities. Mycoscience DOI: 10.1007/s10267011-0165-9.
5. Mends, M. T., E. Yu, S. Riyaz-Ul-Hassan, E. Booth, B. Geary, J. Sears, et al. 2012. An endophytic Nodulisporium sp. producing volatile organic compounds having bioactivity and fuel potential. J. Petrol. Environ. Biotechnol. 3: 3.

6. Page, A., M. K. Tivey, D. S. Stakes, and A. L. Reysenbach. 2008. Temporal and spatial archaeal colonization of hydrothermal vent deposits. Environ. Microbiol. 10: 874-884.

7. Renniger, N. and D. McPhee. 2008. Fuel compositions comprising farnesane and farnesane derivatives and method of making and using same. U.S. Patent No. 7399323.

8. Riyaz-Ul-Hassan, S., G. A. Strobel, E. Booth, B. Knighton, and J. Sears. 2012. Modulation of volatile organic compound formation in the mycodiesel producing endophyte Hypoxylon sp. CI-4. Microbiology 158: 465-473.

9. Romoli, R., M. C. Papaleo, D. de Pascale, M. L. Tutino, L. Michaud, A. LoGiudice, et al. 2011. Characterization of the volatile profile of Antarctic bacteria by using solid-phase microextraction-gas chromatography-mass spectrometry. J. Mass Spectrom. 46: 1051-1059.

10. Staley, J. T., R. W. Castenholz, R. R. Colwell, J. G. Holt, M. D. Kane, N. R. Pace, et al. 1997. The Microbial World: Foundation of the Biosphere. American Academy of Microbiology, Washington DC.

11. Strobel, G. 2006. Harnessing endophytes for industrial microbiology. Curr. Opin. Microbiol. 9: 240-244.

12. Strobel, G., S. K. Singh, S. Riyaz-Ul-Hassan, A. M. Mitchel, B. Geary, and J. Sears. 2011. An endophytic/pathogenic Phoma sp. from creosote bush producing biologically active volatile compounds having fuel potential. FEMS Microbiol. Lett. 320: 87-94.

13. Strobel, G. A. and B. Daisy. 2003. Bioprospecting for microbial endophytes and their natural products. Microbiol. Mol. Biol. Rev. 67: 491-502.

14. Strobel, G. A., E. Dirksie, J. Sears, and C. Markworth. 2001. Volatile antimicrobials from Muscodor albus, a novel endophytic fungus. Microbiology 147: 2943-2950.

15. Strobel, G. A., B. Knighton, K. Kluck, Y. Ren, T. Livinghouse, M. Griffen, et al. 2008. The production of myco-diesel hydrocarbons and their derivatives by the endophytic fungus Gliocladium roseum (NRRL 50072). Microbiology 154: 33193328.

16. Tamura, K., J. Dudley, M. Nei, and S. Kumar. 2007. MEGA4: Molecular evolutionary genetics analysis (MEGA) software version 4.0. Molec. Biol. Evol. 24: 1596-1599.

17. Tomsheck, A., G. A. Strobel, E. Booth, B. Geary, D. Spakowicz, and B. Knighton, et al. 2010. Hypoxylon sp., an endophyte of Perseaindica, producing 1,8-cineole and other bioactive volatiles with fuel potential. Microbial Ecol. 60: 903914.

18. Verma, V. C., R. N. Kharwar, and G. A. Strobel. 2009. Chemical and functional diversity of natural products from plant associated endophytic fungi. Nat. Prod. Commun. 4: 15111532.

19. Yu, X. D., J. Pickett, Y. Z. Ma, T. Bruce, J. Napier, H. D. Jones, and L. Q. Xia. 2012. Metabolic engineering of plant-derived (E)- $\beta$-farnesene synthase genes for a novel type of aphidresistant GM crop plants. J. Int. Plant Biol. 54: 282-299. 